\title{
Target prediction by cascaded self-organizing maps for ligand de-orphaning and side-effect investigation
}

\author{
Daniel Reker ${ }^{*}$, Tiago Rodrigues, Petra Schneider, Gisbert Schneider \\ From 9th German Conference on Chemoinformatics \\ Fulda, Germany. 10-12 November 2013
}

Computational chemogenomics approaches have emerged as a means to predict modulations of biomolecules by ligands. We implemented a method for the prediction of the macromolecular targets of small molecules combining state-of-the-art approaches that compare physicochemical properties and pharmacophoric features of query molecules with known drugs. Investigating similarity from multiple vantage points has been shown to increase the prediction accuracy in a retrospective evaluation. The method has been applied in multiple projects to "de-orphan" molecules with unknown main target and investigate potential side-effects of drug candidates. In a first application, the method identified a molecular scaffold as a potentially privileged structure of druglike compounds for chemoresistant tumor therapy [1]. In a second project, the tool revealed the potential of up to $5 \%$ of known bioactive substances to have unrecognized epigenetic effects by modulating histone deacetylase (HDAC) activity - thereby stressing the importance of probing for epigenetic effects in long-term drug toxicity studies [2].

Published: 11 March 2014

\section{References}

1. Reutlinger $M$, Koch $C P$, Reker $D$, Todoroff $N$, Schneider $P$, Rodrigues $T$, Schneider G: Mol Inf 2013, 32:133-138.

2. Lötsch J, Schneider G, Reker D, Parnham MJ, Schneider P, Geisslinger G, Doehring A: Trends Mol Med 2013.

doi:10.1186/1758-2946-6-S1-P47

Cite this article as: Reker et al:: Target prediction by cascaded selforganizing maps for ligand de-orphaning and side-effect investigation. Journal of Cheminformatics 2014 6(Suppl 1):P47.

Publish with ChemistryCentral and every scientist can read your work free of charge

"Open access provides opportunities to our colleagues in other parts of the globe, by allowing anyone to view the content free of charge."

W. Jeffery Hurst, The Hershey Company.

- available free of charge to the entire scientific community

- peer reviewed and published immediately upon acceptance

- cited in PubMed and archived on PubMed Central

- yours - you keep the copyright

Submit your manuscript here:

http://www.chemistrycentral.com/manuscript/

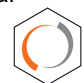

Chemistry Central 